\title{
Pelaksanaan Sasaran Keselamatan Pasien di Rumah Sakit
}

\author{
Christin Butar Butar
}

christinbutarbutar19@gmail.com

\section{Latar Belakang}

Sasaran Keselamatan Pasien merupakan suatu bagian dari Standar Akreditasi Rumah Sakit yang harus dapat diterapkan di rumah sakit yang berguna dalam meningkatkan pelayanan kesehatan yang berkualitas. Pengetahuan tenaga kesehatan dalam Sasaran Keselamatan Pasien terdiri dari ketepatan identifikasi pasien, peningkatan komunikasi yang efektif, peningkatan keamanan obat yang perlu diwaspadai kepastian tepat lokasi, tepat prosedur, dan tepat pasien operasi, pengurangan risiko infeksi terkait pelayanan kesehatan, pengurangan risiko pasien jatuh. Bagi tenaga kesehatan khususnya dokter dan perawat diwajibkan untuk mengetahui tentang Sasaran Keselamatan Pasien.

Keselamatan (safety) telah menjadi isu global termasuk juga untuk rumah sakit. Menurut Nursalam (2011:307), Keselamatan pasien (patient safety) merupakan suatu variabel untuk mengukur dan mengevaluasi kualitas pelayanan keperawatan yang berdampak terhadap pelayanan kesehatan. Program keselamatan pasien bertujuan menurunkan angka Kejadian Tidak Diharapkan (KTD) yang sering terjadi pada pasien selama dirawat di rumah sakit sehingga sangat merugikan baik pasien sendiri dan pihak rumah sakit. Sasaran Keselamatan Pasien (SKP) menjadi indikator standar dasar yang utama dalam penilaian Akreditasi Rumah Sakit versi 2012 (KARS, 2013). Ada enam sasaran keselamatan pasien yaitu Ketepatan identifikasi pasien; Peningkatan komunikasi yang efektif; Peningkatan keamanan obat yang perlu diwaspadai; Kepastian tepatlokasi, tepat-prosedur, tepat-pasien operasi; Pengurangan risiko infeksi terkait pelayanan kesehatan; dan Pengurangan risiko pasien jatuh (Permenkes Nomor 1691, 2011). Keselamatan pelayanan di rumah sakit salah satunya dimulai dari ketepatan identifikasi pasien. Karena salah identifikasi pasien diidentifikasi sebagai akar penyebab banyak kesalahan yang terjadi (WHO) 


\section{Metode}

Metode ini menggunakan metode kuantitatif.berdasarkan dari penjelasan yang didapat dari sumber dan referensi dimana maksudnya dengan cara mengumpulkan sebanyak-banyaknya data untuk dianalisis. yaitu dengan Literature review ini dengan menganalisis yang berfokus pada sasaran keselamatan pasien. Adapun tinjauan literatur yang digunakan seperti buku teks, jurnal dan e-book.

\section{Hasil}

Keselamatan pasien merupakan prioritas utama untuk dilaksanakan dan hal tersebut terkait dengan isu mutu dan citra perumahsakitan (Depkes, 2011). Keselamatan pasien di rumah sakit (KPRS) adalah sistem pelayanan dalam suatu Rumah sakit yang memberikan asuhan pasien menjadi lebih aman, termasuk didalamnya mengukur resiko, identifikasi dan pengelolahan resiko terhadap pasien analisa insiden, kemampuan untuk belajar dan menindaklanjuti insiden serta menerapkan solusi untuk mengurangi resiko (WHO,2004). Oleh karena itu diperlukan komitmen dan ethis dalam keperawatan. Keselamatan pasien merupakan suatu system yang sangat dibutuhkan dan dengan adanya system ini diharapkan dapat meminimalisir kesalahan dalam penanganan pasien baik pada pasien UGD, rawat inap maupun pasien poliklinik (PERSI, 2008).

WHO Menyusun sasaran keselamatan pasien internasional, sasaran tersebut ,menjadi acuan lembaga akreditas rumah sakit dalam menilai kinerja keselamatan pasien di rumah sakit. Terdapat 6 hal yang menjadi sasaran keselamatan pasien Keenam sasaran keselamatan pasien tersebut kemudian dikembangkan menjadi elemen penilaian bagi rumah sakit agar memudahkan ukuran ketercapaian tujuan tersebut. Sasaran keselamatan pasien meliputi tercapainya hal-hal sebagai berikut : peningkatan identifikasi pasien, peningkatan komunikasi yang efektif, peningkatan keamanan obat yang peerlu diwaspadai, kepastian tepat-lokasi, tepat-prosedur, tepat pasien operasi, pengurangan resiko infeksi terkait pelayanan kesehatan kesehatan dan pengurangan resiko pasien jatuh. 


\section{Pembahasan}

Setiap rumah sakit wajib mengupayakan pemenuhan sasaran keselamatan pasien (Permenkes 2011). Sasaran keselamatan pasien meliputi tercapainya hal-hal sebagai berikut : peningkatan identifikasi pasien, peningkatan komunikasi yang efektif, peningkatan keamanan obat yang peerlu diwaspadai, kepastian tepat-lokasi, tepat-prosedur, tepat pasien operasi, pengurangan resiko infeksi terkait pelayanan kesehatan kesehatan dan pengurangan resiko pasien jatuh.

WHO Menyusun sasaran keselamatan pasien internasional, sasaran tersebut ,menjadi acuan lembaga akreditas rumah sakit dalam menilai kinerja keselamatan pasien di rumah sakit. Terdapat 6 hal yang menjadi sasaran keselamatan pasien Keenam sasaran keselamatan pasien tersebut kemudian dikembangkan menjadi elemen penilaian bagi rumah sakit agar memudahkan ukuran ketercapaian tujuan tersebut.

\section{Sasaran 1 : Mengidentifikasi Pasien Dengan Benar}

Standar SKP .1 Rumah sakit menetapkan regulasi untuk menjamin ketepatan (akurasi) identifikasi pasien.

Elemen Penilaian SKP.1

a. Ada regulasi yang mengatur pelaksanaan identifikasi pasien.

b. Identifikasi pasien dilakukan dengan menggunakan minimal 2 (dua) identitas dan tidak boleh menggunakan nomor kamar pasien atau lokasi dirawat sesuai dengan regulasi rumah sakit

c. Identifikasi pasien dilakukan sebelum dilakukan tindakan, prosedur diagnostic, dan terapeutik.

d. Pasien diidentifikasi sebelum pemberian obat, darah, produk darah, pengambilan specimen, dan pemberian diet.

e. Pasien diidentifikasi sebelum pemberian radioterapi, menerima cairan intravena, hemodialisis, pengambilan darah atau pengambilan specimen lain untuk pemeriksaan klinik, katerisasi jantung, prosedur radiologi diagnostic, dan identifikasi terhadap pasien koma.

\section{Sasaran 2 : Meningkatkan Komunikasi Yang Efektif}

Standar SKP.2 Rumah sakit menetapkan regulasi untuk melaksanakan proses meningkatan efektivitas komunikasi verbal atau komunikasi melalui telepon antar- PPA

\section{Elemen Penilaian SKP.2}

a. Ada regulasi tentang komunikasi efektif antarprofesional pemberi asuhan.

b. Ada bukti pelatihan komunikasi efektif antarprofesional pemberi asuhan.

c. Pesan secara verbal atau verbal lewat telpon ditulis lengkap dibaca ulang oleh penerima pesan, dan dikonfirmasi oleh pemberi pesan 
d. Penyampaian hasil pemeriksaan diagnostic secara verbal ditulis lengkap, dibaca ulang dan dikonfirmasi oleh pemberi pesan secara lengkap

Standar SKP.2.1 Rumah sakit menetapkan regulasi untuk proses pelaporan hasil pemeriksaan diagnostic kritis.

Elemen Penilaian SKP 2.1

a. Rumah sakit menetapkan besaran nilai kritis hasil pemeriksaan diagnostik dan hasil diagnostic kritis

b. Rumah sakit menetapkan siapa yang harus melaporkan dan siapa yang harus menerima nilai kritis hasil pemeriksaan diagnostic dan dicatat di rekam medis.

Standar SKP. 2.2 Rumah sakit menetapkan dan melaksanakan proses komunikasi "serah terima" (hand over)

Elemen Penilaian SKP 2.1

a. Ada bukti catatan tentang hal-hal kritial komunikasikan di antara professional pemberi asuhan pada waktu dilakukan serah terima pasien (hand over)

b. Formular, alat dan metode ditetapkan untuk mendukung proses serah terima pasien (hand over) bila mungkin melibatkan pasien.

c. Ada bukti dilakukan evaluasi tentang catatan komunikasi yang terjadi waktu serah terima pasien untuk memperbaiki proses.

\section{Sasaran 3 : Meningkatkan Keamanan Obat - Obatan Yang Harus Diwaspadai (High Alert Medications)}

Standar SKP. 3 Rumah sakit menetapkan regulasi untuk melaksanakan proses menongkatkan keamanan terhadap obat- obat yang perlu diwaspadai.

Elemen Penilaian SKP.3

a. Ada regulasi tentang penyedian, penyimpanan, penataan, penyiapan, dan penggunaan obat yang perlu diwaspadai

b. Rumah sakit mengimplementasikan regulasi yang telah dibuat.

c. Di rumah sakit tersedia daftar semua obat yang perlu diwaspadai

d. Tempat penyimpanan, pelebelan dan penyimapanan obat yang perlu diwaspadai termasuk obat NORUM diatur di tempat aman.

Elemen Penilaian SKP. 3.1

a. Rumah sakit menetapkan regulasi untuk melaksanakan proses mencegah kekuraang hati-hatian dalam mengelola elektrolit konsentrat.

b. Elektrolit konsentrat hanya tersedia di unit kerja/instalasi farmasi atau depo farmasi 


\section{Sasaran 4 : Memastikan Lokasi Pembedahan Benar, Prosedur Yang Benar, Pembedahan Pada Pasien Yang Benar}

Standar SKP.4 Rumah sakit memastikan Tepat-Lokasi, Tepat-Prosedur dan Tepat-Pasien sebelum menjalani tindakan atau prosedur

\section{Elemen Penilaian SKP.4}

a. Ada regulasi untuk melaksanakan penandaan lokasi operasi atau tindakan invasive (site marking)

b. Rumah sakit menggunakan suatu tanda yang jelas dan dimengerti untuk identifikasi lokasi operasi dan melibatkan pasien di dalam proses penandaan

c. Rumah sakit menggunakan suatu checklist atau proses lain untuk memverifikasi saat preoperasi tepat lokasi, tepat prosedur, tepat pasien dan semua dokumen serta peralatan yang diperlukan tersedia, tepat dan fungsional.

d. Tim operasi yang lengkap menerapkan dan mencatat prosedur "sebelum insisi/ time out" tepat sebelum dimulai suatu prosedur/ Tindakan pembedahan.

e. Kebijakan dan prosedur dikembangkan untuk mendukung proses yang seragam untuk memastikan tepat lokasi, tepat prosedur, dan tepat pasien termasuk prosedur medis dan dental yang dilaksanakan di luar kamar operasi.

\section{Sasaran 5 : Pengurangan Resiko Infeksi Terkait Pelayanan Kesehatan}

\section{Elemen Penilaian SKP.5}

a. Rumah sakit mengadopsi atau mengadaptasi pedoman hand hygiene terbaru yang diterbitkan dan sudah diterima secara umum

b. Rumah sakit menerapkan program hand hygiene yang efektif

c. Kebijakan atau prosedur dikembangkan untuk mengarahkan pengurangan secara berkelanjutan risiko dari infeksi yang terkait pelayanan kesehatan.

d. Staf rumah sakit dapat melakukan cuci tangan sesuai dengan prosedur

e. Prosedur disinfeksi di rumah sakit dilakukan sesuai dengan regulasi infeksi terkait pelayanan Kesehatan

f. Ada bukti rumah sakit melaksanakan evaluasi terhadap upaya menurunkan angka infeksi terkait pelayanan Kesehatan 


\section{Sasaran 6 : Mengurangi Risiko Cedera Pasien Akibat Terjatuh}

Standar SKP.6 Rumah sakit melaksanakan upaya mengurangi risiko cedera akibat pasien jatuh.

\section{Elemen Penilaian SKP.6}

a. Rumah sakit menerapkan proses asesmen awal atas pasien terhadap risiko jatuh dan melakukan asasmen ulang pasien bila diindikasi terjadi perubahan kondisi atau pengobatan dan lain-lain.

b. Langkah-langkah diterapkan untuk mengurangi risiko jatuh bagi mereka yang pada hasil asesmen dianggap berisiko jatuh,

c. Langkah- Langkah dimonitor hasilnya, baik keberhasilan pengurangan cedera akibat jatuh dan dampak dari kejadian tidak diharapkan.

\section{Penutup}

Sasaran Keselamatan Pasien merupakan suatu bagian dari Standar Akreditasi Rumah Sakit yang harus dapat diterapkan di rumah sakit yang berguna dalam meningkatkan pelayanan kesehatan yang berkualitas. Pengetahuan tenaga kesehatan dalam Sasaran Keselamatan Pasien terdiri dari ketepatan identifikasi pasien, peningkatan komunikasi yang efektif, peningkatan keamanan obat yang perlu diwaspadai kepastian tepat lokasi, tepat prosedur, dan tepat pasien operasi, pengurangan risiko infeksi terkait pelayanan kesehatan, pengurangan risiko pasien jatuh. Bagi tenaga kesehatan khususnya dokter dan perawat diwajibkan untuk mengetahui tentang Sasaran Keselamatan Pasien.

WHO Menyusun sasaran keselamatan pasien internasional, sasaran tersebut ,menjadi acuan lembaga akreditas rumah sakit dalam menilai kinerja keselamatan pasien di rumah sakit. Terdapat 6 hal yang menjadi sasaran keselamatan pasien Sasaran keselamatan pasien meliputi tercapainya hal-hal sebagai berikut : peningkatan identifikasi pasien, peningkatan komunikasi yang efektif, peningkatan keamanan obat yang peerlu diwaspadai, kepastian tepat-lokasi, tepat-prosedur, tepat pasien operasi, pengurangan resiko infeksi terkait pelayanan kesehatan kesehatan dan pengurangan resiko pasien jatuh. 


\section{Daftar Pustaka}

Angelia, Kandou, Tilaar. (2014). Analisis Pelaksanaan Standart Sasaran Keselamatan Pasien di IGD. Jurnal JIKMU, Vol 5(2)

Bernadeta, Ani. (2015). Pengetahuan Perawat Tentang keselamatan Pasien Rumah Sakit. Jurnal Care, Vol 3(1)

Diah Arrum, Salbiah, Murniatik. (2015). Pengetahuan Tenaga Kesehatan Dalam Sasaran Keselamatan Pasien Di Rumah Sakit Sumatera Utara. Idea Nursing Journal Vol 6 (2)

Hadi, Irwan. 2017. Managemen Keselamatan Pasien. Yogyakarta : CV Budi Utama

Iswati. (2013). Penerapan Sasaran Keselamatan Pasien Di Rumah Sakit. Jurnal Keperawatan Adi Husada

Mardika, Zuhrotunida, Syahridal. (2016). Implementasi Sasaran Keselamatan Pasien di Ruang Inap RSU Kabupaten Tangerang. Jurnal JKFT, Vol 2, 59-69

Nandahani. (2017). Penerapan Standar Keselamatan Pasien RSUD Provinsi Nusa Tenggara Barat. Jurnal Kesehatan Poltekkes Ternate, Vol 11 (2), 93-108

Nur Malya Isnaini, Roffi. (2014). Pengalaman Perawat Pelaksana Dalam Menerapkan Keselamatan Pasien. Jurnal Managemen Keperawatan, Vol 2(1), 30-37

Reno Afriza, Yuni Lestari, Husna Yetti (2018).Analisis Pelaksanaan Sasaran Keselamatan Pasien di RSUD Padang Sidempuan. Jurnal Kesehatan Andalas.Vol 7

Simamora, R. H. (2018). Buku ajar keselamatan pasien melalui timbang terima pasien berbasis komunikasi efektif: SBAR. Medan: USUpress.

Simamora, R. H. (2020). Learning of Patient Identification in Patient Safety Programs Through Clinical Preceptor Models. Medico Legal Update, 20(3), 553-556.

Viera Wardhani. 2017. Managemen Keselamatan Pasien Di Rumah Sakit. Malang : UB Press 